\title{
RESEARCH
}

Open Access

\section{Adipose mesenchymal stem cell transplantation alleviates spinal cord injury- induced neuroinflammation partly by suppressing the Jagged1/Notch pathway}

Zhilai Zhou ${ }^{1+}$, Xiaobo Tian ${ }^{2,1+}$, Biling Mo ${ }^{3}$, Huali Xu', Li Zhang ${ }^{1}$, Lishan Huang ${ }^{1}$, Shun Yao ${ }^{1}$, Zixiang Huang ${ }^{1}$, Yeyang Wang ${ }^{1}$, Huan $\mathrm{Xie}^{2}$, Liwei $\mathrm{Xu}^{2,1}$ and Hui Zhang ${ }^{1,2^{*}}$ (D)

\begin{abstract}
Background: The therapeutic effects of adipose-derived mesenchymal stem cell (ADSC) transplantation have been demonstrated in several models of central nervous system (CNS) injury and are thought to involve the modulation of the inflammatory response. However, the exact underlying molecular mechanism is poorly understood. Activation of the Jagged1/Notch signaling pathway is thought to involve inflammatory and gliotic events in the CNS. Here, we elucidated the effect of ADSC transplantation on the inflammatory reaction after spinal cord injury $(\mathrm{SCl})$ and the potential mechanism mediated by Jagged1/Notch signaling pathway suppression.

Methods: To evaluate the therapeutic effects of ADSC treatment and the potential inhibitory effects of ADSCs on Notch signaling, mice were subjected to contusion SCl, and GFP-labeled ADSCs were injected into the lesion site immediately after the injury. Locomotor function, spinal cord tissue morphology, and the levels of Notch-related proteins and proinflammatory transcripts were compared between groups. To validate the hypothesis that the therapeutic effects of ADSCs are partly due to Notch1 signaling inhibition, a Jagged1 small interfering RNA (siRNA) was injected into the spinal cord to knock down Jagged1/Notch signaling. Neuronal staining and analyses of microglia/macrophage activation and signaling pathways were performed.

(Continued on next page)
\end{abstract}

\footnotetext{
*Correspondence: spinelove@163.com

${ }^{\dagger}$ Zhou Zhilai and Tian Xiaobo contributed equally to this work.

${ }^{1}$ The Spine Department, Orthopaedic Center, Guangdong Second Provincial General Hospital, Guangzhou, China

${ }^{2}$ The Second School of Clinical Medicine, Southern Medical University, Guangzhou, China

Full list of author information is available at the end of the article
}

(c) The Author(s). 2020 Open Access This article is licensed under a Creative Commons Attribution 4.0 International License, which permits use, sharing, adaptation, distribution and reproduction in any medium or format, as long as you give appropriate credit to the original author(s) and the source, provide a link to the Creative Commons licence, and indicate if changes were made. The images or other third party material in this article are included in the article's Creative Commons licence, unless indicated otherwise in a credit line to the material. If material is not included in the article's Creative Commons licence and your intended use is not permitted by statutory regulation or exceeds the permitted use, you will need to obtain permission directly from the copyright holder. To view a copy of this licence, visit http://creativecommons.org/licenses/by/4.0/ The Creative Commons Public Domain Dedication waiver (http://creativecommons.org/publicdomain/zero/1.0/) applies to the data made available in this article, unless otherwise stated in a credit line to the data. 
(Continued from previous page)

Results: We demonstrated that ADSCs survived in the injured spinal cord for at least 28 days without differentiating into glial or neuronal elements. ADSC treatment resulted in significant downregulation of proinflammatory mediator expression and reduced ionized calcium-binding adapter molecule 1 (IBA1) and ED-1 staining in the injured spinal cord, eventually improving functional recovery. The augmentation of the Jagged1/Notch signaling pathway after SCl was suppressed by ADSC transplantation. The inhibition of the Jagged1/Notch signaling pathway by Jagged1 siRNA resulted in decreases in SCl-induced proinflammatory cytokines and the activation of microglia and an increase in the survival of neurons. Furthermore, Jagged1 knockdown suppressed the phosphorylation of JAK/STAT3 in astrocytes following $\mathrm{SCl}$.

Conclusion: The results of this study demonstrated that the therapeutic effects of ADSCs in SCI mice were partly due to Jagged1/Notch signaling pathway inhibition and a subsequent reduction in JAK/STAT3 phosphorylation in astrocytes.

Keywords: Adipose, Mesenchymal stem cell, Spinal cord injury, Neuroinflammation, Jagged1, Notch

\section{Introduction}

Spinal cord injury (SCI) is one of the most challenging clinical issues, with an incidence of 15-40 cases per million people worldwide every year [1]. SCI induces a cascade of secondary tissue damage that limits spontaneous neural tissue regeneration, often leading to severe and permanent paralysis; despite great efforts, however, SCI repair remains a major therapeutic challenge for researchers [2]. Recent advances in SCI research have indicated that the neuroinflammatory process caused by injuries to the central nervous system (CNS), including the infiltration of macrophages into the injured tissue and the secretion of inflammatory cytokines, is one of the major causes of mortality and unfavorable outcomes in SCI patients $[3,4]$.

With the development of stem cell technology, the immunomodulatory function of stem cell transplantation, especially that of mesenchymal stem cells (MSCs), also known as mesenchymal stromal cells, has become a hot topic for the treatment of SCI [5]. MSCs have widely been used in experimental and clinical settings and have exhibited tangible therapeutic potential in various central nervous system (CNS) conditions, such as ischemic stroke [6, 7], multiple sclerosis [8], and SCI [9, 10]. It has been reported that MSC transplantation can reduce inflammatory reactions in pathological processes [11, 12]. MSCs were originally isolated from the bone marrow, and similar populations have been isolated from other tissues. Our previous study demonstrated that adipose tissue-derived mesenchymal stem cells (ADSCs) are a superior alternative to MSCs from other tissues because of their abundant availability and excellent expansion and proliferative capacities [13]. Numerous studies have demonstrated that ADSCs can alleviate the infiltration of ED1-positive macrophages and suppress the inflammatory response after CNS injury [14, 15]. However, the precise mechanism underlying the effects of transplanted MSCs on the inflammatory reaction following CNS is still unclear.
The Notch1 pathway is a highly conserved signaling system that is critical for cell fate decisions, tissue morphogenesis, and many cellular processes [16, 17]. The interaction of Notch receptors with their ligand (Delta1 or Jagged1) leads to the proteolytic cleavage of the transmembrane Notch receptor, giving rise to the release of the Notch intracellular domain (NICD) from the membrane, after which the NICD migrates into the nucleus. In the nucleus, NICD interacts with the transcription factor RBP-JK, which promotes the expression of transcriptional activators and thereby induces the expression of target genes, mainly hairy and enhancer of split (Hes) isoforms 1 and 5 [18, 19]. A growing body of work has demonstrated that Notch1 signaling is involved in the induction of the inflammatory response in various diseases. Pharmacological or transgenic interference with Notch signaling can ameliorate neuroinflammation and support neuronal survival [20-23]. In addition, MSC transplantation has been reported to suppress Notch1 signaling in various systemic diseases, such as ischemic stroke [24], inflammatory bowel disease [25], lupus [26], and brain injury [27]. However, the contributions of MSC administration to the inhibition of the Notch1 signaling pathway after SCI have not been explored.

Signal transducer and activator of transcription 3 (STAT3) is a critical regulator of astrogliosis and scar formation after CNS injury [28]. The activation of STAT3 via phosphorylation by Janus kinases (JAKs) has been demonstrated in a variety of disease models, including models of Alzheimer's and Huntington's diseases [29], cerebral ischemia [30], and SCI [31]. A large number of studies have indicated a strong association between Notch and JAK/STAT3 signaling, and a change in Notch expression can alter STAT3 phosphorylation and activity [32-34]. However, whether JAK/STAT3 signaling participates in the suppressive effects of MSCs on Notch1 expression after SCI is still unclear. 
In this study, we investigated the spatiotemporal expression of Notch signaling in a mouse model of SCI and then elucidated the signaling pathways underlying the functional recovery of SCI mice treated with ADSC transplantation.

\section{Materials and methods}

All the mice used in this experiment were purchased from the Laboratory Animal Center of the Southern Medical University (Guangzhou, China). All experimental protocols were approved by the Institutional Animal Care and Use Committee of Guangdong Second Provincial General Hospital, Guangzhou, China.

\section{Animals and experimental groups}

The experiments were performed as described below.

\section{Part 1}

To evaluate the effects of ADSC treatment on the recovery of SCI mice and the activity of Notch1 signaling after $\mathrm{SCI}$, a total of 132 8- to 12-week-old female C57Bl/6 mice were divided into three experimental groups: (i) the sham group, which underwent laminectomy without SCI; (ii) the control group, which underwent SCI followed by injection of PBS without cells; and (iii) the ADSC group, which underwent SCI followed by transplantation of ADSCs. The number of mice in each experimental group is listed in Additional file 1.

\section{Part 2}

To validate the hypothesis that the inhibition of the Jagged1/Notch signaling pathway participates in the protective mechanism of SCI, a lentiviral vector containing Jagged1 siRNA (Shanghai Lianfeng Biotechnology Co., Ltd., China) was injected into the spinal cord $72 \mathrm{~h}$ before SCI modeling to inhibit the Jagged1/Notch pathway. A total of 104 female $\mathrm{C} 57 \mathrm{Bl} / 6$ mice were divided into four experimental groups: (i) the sham group; (ii) the $\mathrm{SCI}+\mathrm{PBS}$-injected (control) group; (iii) the $\mathrm{SCI}+$ Jagged1 siRNA-injected group, which received an injection of $2.5 \mu \mathrm{l}$ of lentiviral vector $\left(4 \times 10^{8} \mathrm{IU} / \mathrm{ml}\right) 3$ days before $\mathrm{SCI}$; (iv) and the SCI+scramble siRNA-injected group, which was used as controls for the Jagged1 siRNAinjected group and received an injection of a lentiviral vector containing scramble siRNA. The number of mice in each experimental group is listed in Additional file 1.

\section{Preparation of ADSCs}

ADSCs were isolated as previously described [35]. Adipose tissues from the inguinal pads were dissected, and upon the removal of debris, the tissues were then enzymatically dissociated with $0.1 \%$ collagenase type I (Sigma, St. Louis, MO, USA) at $37^{\circ} \mathrm{C}$ for $60 \mathrm{~min}$ under shaking. The digested tissue was centrifuged at 1500 rpm for $5 \mathrm{~min}$ and resuspended in saline for a total of 2 times. Isolated cells were resuspended in Dulbecco's modified Eagle's medium (DMEM; Gibco, Grand Island, NY, USA) with $10 \%$ fetal bovine serum (Gibco) and maintained at $37^{\circ} \mathrm{C}$ in $5 \% \mathrm{CO}_{2}$. Following overnight incubation, the flasks were washed extensively with PBS to remove non-adherent cells. Fluorescence-activated cell sorting analysis was used to identify the phenotype of the cells. CD29, CD44, CD90, and CD45 were detected to confirm the MSC identity of the cells. ADSCs at passage 3 were used in this study. To track the grafted cells in vivo, ADSCs were infected with GFP-expressing lentivirus as described previously [36]. Transduction efficiency was assessed by the detection of the GFP signal intensity. GFP-modified ADSCs were detached with $0.125 \%(\mathrm{w} / \mathrm{v})$ trypsin, suspended in phosphate-buffered saline (PBS), and kept on ice until use.

\section{Primary neuron culture, OGD stress model, and co-culture systems}

Neurons were cultured from the cerebral cortices of neonatal mice brains (day 1). Cultures were prepared according to a previously described procedure with some modifications [37]. Briefly, the cerebral cortex was dissociated in $\mathrm{Ca}^{2+}$ and $\mathrm{Mg}^{2+}$ free Hank's Balanced Saline Solution (Life Technologies; Grand Island, NY, USA) containing $0.2 \%$ trypsin for $15 \mathrm{~min}$. The cell suspensions were washed and resuspended with Dulbecco's modified Eagle's medium (DMEM; Gibco) with 5\% fetal bovine serum (FBS; Gibco). The neurons were seeded into poly-L-lysine precoated 24-well plates in a density of $10^{4}$ cells/well. Following cell attachment (3-6h after plating), the culture medium was replaced with a neurobasal medium (Invitrogen, Waltham, MA, USA) containing 2\% B-27 (Gibco). Three days later, the neuron culture medium was replaced with Hank's Balanced Salt Solution. Then, the cells were placed in an incubator (Thermo Forma 3111, Thermo Scientific) containing $5 \% \mathrm{O}_{2}$ and $95 \% \mathrm{~N}_{2}$ at $37^{\circ} \mathrm{C}$ for $6 \mathrm{~h}$ to establish an oxygen and glucose deprivation (OGD) model. Neurons that were not subjected to OGD served as controls. For generating a co-culture system, $2 \times 10^{6}$ ADSC were seeded together with the OGD neurons in a total of $0.5 \mathrm{~mL}$ media.

\section{In vitro Jagged-1 Fc and Jagged-1 siRNA treatments}

To activate Jagged-1/Notch signaling, ADSC and neurons were co-cultured in $0.5 \mathrm{ml}$ DMED containing $1 \mu \mathrm{g} /$ ml Jagged-1 Fc (Abcam, Cambridge, MA, USA) for $24 \mathrm{~h}$. To block Jagged-1/Notch signaling, neurons were transfected with Jagged-1 siRNA for $24 \mathrm{~h}$ according to the manufacturer's protocol, and then, these cells were cocultured with ADSC for $24 \mathrm{~h}$. 


\section{Enzyme-linked immunosorbent assay}

The levels of IL-6, IL-1 $\beta$, and TNF- $\alpha$ cytokine release in the culture media from the various treatment groups were measured using an ELISA kit (R\&D, Minneapolis, MN, USA). The colorimetric absorbance was recorded at a wavelength of $450 \mathrm{~nm}$. The IL-6, IL-1 $\beta$, and TNF- $\alpha$ concentrations were calculated according to a standard curve constructed for each assay, and each assay was performed in triplicate.

\section{SCI model and ADSC transplantation}

After anesthetization by inhalation of $1.5 \%$ isoflurane, the animals underwent dorsal laminectomy at the tenth thoracic vertebral level (T10), and the spinal cord and dura mater were exposed. A moderate contusion injury ( $50 \mathrm{kdyn})$ of the spinal cord was produced using the Infinite Horizon Impactor (Precision Systems and Instrumentation) as previously described [38]. After injury, depending on the experimental group, $3 \mu \mathrm{l}$ of saline- or GFP-labeled ADSCs $\left(1 \times 10^{6}\right.$ cells $)$ was injected directly into the SCI epicenter with a Hamilton syringe positioned with a stereotaxic instrument (Kopf Instruments, Tujunga, CA, USA) at a flow rate of $0.4 \mu \mathrm{l} / \mathrm{min}$. The overlying muscle layers were then sutured, and the cutaneous layers were stapled. The bladders of the mice were manually and gently expressed to prevent urinary tract infection until the reflexive control of micturition was restored. Depending on the experiment performed, the SCI mice were killed by transcardial perfusion $1,3,7$, 14 , or 28 days post-contusion.

\section{Behavioral analyses}

Functional recovery after SCI was assessed with the Basso Mouse Scale (BMS) scores [39]. Mice were tested on postoperative days $1,7,14,21$, and 28 for the duration of the experiments. All animals were placed in an open field and simultaneously observed by two examiners who were blinded to the identity of the animals.

\section{Western blot analysis}

According to experimental design, mice $(n=4)$ were transcardially perfused with ice-cold PBS $(0.1 \mathrm{M}, \mathrm{pH}$ 7.4), and approximately $5 \mathrm{~mm}$ of each spinal cord segment, including the injury site, was collected and stored at $-80^{\circ} \mathrm{C}$ until further analysis. Equal amounts of protein $(50 \mu \mathrm{g})$ from different samples were separated by sodium dodecyl sulfate/polyacrylamide gel electrophoresis and transferred to nitrocellulose membranes. The blots were incubated with the following primary antibodies: Notch1 (mouse, 1:1000, Santa Cruz Biotechnology, Dallas, TX, USA), RBP-JK (mouse, 1:1000, Santa Cruz Biotechnology), NICD (rabbit, 1:2000, Abcam, Cambridge, MA, USA), JAK (rabbit, 1:2000, Cell Signaling Technology, Inc., Beverly, MA, USA), p-STAT3 (rabbit, 1:2000,
Cell Signaling Technology), and STAT3 (rabbit, 1:2000, Cell Signaling Technology). The primary antibodies were further incubated with appropriate secondary antibodies $(1: 10,000)$ for $2 \mathrm{~h}$ at room temperature. GAPDH was used as an internal control (Sigma, St. Louis, MO, USA). The reactive bands were visualized using enhanced chemiluminescence reagent (Thermo Fisher Scientific, Waltham, USA), and the density of the protein bands was semiquantified using The ImageJ software.

\section{Real-time polymerase chain reaction}

RNA was isolated using TRIzol Reagent (TaKaRa Biotechnology, Dalian, China), and reverse transcripts were synthesized from $1 \mu \mathrm{g}$ of total RNA using the PrimeScript 1st Strand cDNA Synthesis Kit (TaKaRa Biotechnology, Dalian, China) according to the manufacturer's instructions. Amplification was performed using the ABI 7500 Real-Time PCR System (Applied Biosystems, Foster City, CA, USA) with a two-step PCR protocol (preincubation of $10 \mathrm{~min}$ at $95^{\circ} \mathrm{C}$ followed by 30 cycles at $95^{\circ} \mathrm{C}$ for $15 \mathrm{~s}$ and $60^{\circ} \mathrm{C}$ for $1 \mathrm{~min}$ ). The list of primer sequences is provided in Table 1. After normalization to $\beta$-actin mRNA, the comparative threshold $(\Delta \mathrm{CT})$ method was used to examine the relative quantification of the samples (Relative Quantitation computer software; Applied Biosystems). Fold expression changes were calculated using the equation $2 \Delta \Delta \mathrm{CT}$.

\section{Hematoxylin and eosin staining}

We performed hematoxylin and eosin (H\&E) staining to examine the lesion areas in the injured spinal cords of the control group and ADSC group at 28 days postinjury $(n=4)$. H\&E staining was performed in accordance with a well-established protocol. After curing of the mounting medium, the sections were examined under a light microscope (Zeiss, Germany). The size of the cavity formed at the injury epicenter was manually outlined for each section and analyzed using the ImageJ software.

Table 1 Primers for real-time PCR

\begin{tabular}{ll}
\hline Gene & Sequence \\
\hline $\mathrm{IL}-6$ & GAGTCCTTCAGAGAGATACAGAAAC \\
& TGGTCTTGGTCCTTAGCCAC \\
$\mathrm{IL-1 \beta}$ & GAAATGCCACCTITGACAGTG \\
& CTGGATGCTCTCATCAGGACA \\
TNF-a & CCCTCACACTCAGATCATCTTCT \\
& GCTACGACGTGGGCTACAG \\
$\beta$-actin & ATCAACGACCCCTTCATTGACC \\
& CCAGTAGACTCCACGACATACTCAG
\end{tabular}




\section{Immunostaining}

The mice were anesthetized and transcardially perfused with $4 \%$ paraformaldehyde in PBS on days $1,3,7,14$, and 28 after SCI. The spinal cords were post-fixed in paraformaldehyde overnight, embedded in paraffin, sectioned in the sagittal or transverse plane at a thickness of $4 \mu \mathrm{m}$, and deparaffinized and rehydrated by subsequent immersion in xylene ( 2 times, $10 \mathrm{~min}$ ), $100 \%$ ethanol (5 times, $1 \mathrm{~min}$ ), $95 \%$ ethanol (5 min), 90\% ethanol (3 $\mathrm{min}), 80 \%$ ethanol ( $3 \mathrm{~min}$ ), 70\% ethanol ( $3 \mathrm{~min}$ ), 80\% ethanol (5 min), and $\mathrm{H}_{2} \mathrm{O}(5 \mathrm{~min})$. The following primary antibodies were used: GFP (1:50, mouse, Santa Cruz Biotechnology), Jagged1 (mouse, 1:50, Santa Cruz Biotechnology), NICD (rabbit, 1:200, Cell Signaling Technology), GFAP (mouse, 1:1000, Sigma-Aldrich, Shanghai; rabbit, 1:1000, Millipore, Billerica, MA, USA), IBA1 (rabbit, 1:1000, Abcam), NeuN (1:1000, mouse, Millipore; 1:100, rabbit, Beyotime, Bejing, China), NF200 (rabbit, 1:800, Abcam), ED1 (mouse, 1:200, Millipore), activated caspase-3 (rabbit, 1:100, Cell Signaling Technology), and pSTAT3 (rabbit, 1:200, Cell Signaling Technology). Antigen retrieval was performed with sodium citrate buffer $(10 \mathrm{mM}$ sodium citrate, $\mathrm{pH} 6,0.01 \%$ Triton) for $20 \mathrm{~min}$ at $96^{\circ} \mathrm{C}$ in a microwave. For immunostaining with antibodies against Jagged1 (mouse, 1:50, Santa Cruz Biotechnology) and NICD (rabbit, 1:200, Cell Signaling Technology), the mounted sections were subjected to sodium citrate buffer-based $(10 \mathrm{mM}$ sodium citrate, $\mathrm{pH} 6$, in $0.01 \%$ Triton) antigen retrieval in a preheated pressure cooker for $5 \mathrm{~min}$. The secondary antibodies (1:500) that were used were Alexa Fluor 594conjugated goat anti-rabbit (Thermo Fisher, Waltham, MA, USA) and Alexa Fluor 488-conjugated goat antimouse (Thermo Fisher). Finally, the tissues were counterstained with 4'6-diamidino-2-phenylindole (DAPI) (Sigma, St. Louis, MO, USA) and observed under a fluorescence microscope (Leica-DMI8, Leica Microsystems, Germany).

\section{Quantitative analyses of stained tissue sections}

To quantify cells of interest in immunostained sections, we obtained images of the stained sections by fluorescence microscopy (model TCS SP2; Leica Microsystems). Three slices per mouse and three fields from each slice were used for quantification; we manually outlined the cells and quantified them using the ImageJ software. The threshold values were maintained at a constant level for all analyses using the ImageJ software. ED1-positive, pSTAT3-positive, IBA1-positive, and NICD-positive areas were divided by the area of the image and are expressed as percentages. The number of NeuN-positive cells and activated caspase 3-positive cells was manually counted at $\times 400$ magnification. The average number of activated caspase 3-positive cells expressing NeuN in these images was quantified.

\section{Statistical analysis}

Statistical analysis was performed using SPSS 20.0 for Windows (Inc., Chicago, IL, USA). All data in this study are presented as the mean \pm SEM. Data from more than 2 groups were analyzed by one-way analysis of variance (ANOVA), followed by Bonferroni post hoc testing. The differences between the 2 groups were analyzed by Student's $t$ tests. Differences were deemed statistically significant at $P<0.05$.

\section{Results}

\section{ADSC treatment improved functional recovery after SCI}

Locomotor functional recovery was evaluated using the Basso, Beattie, Bresnahan-derived Basso Mouse Scale (BMS) locomotor rating scale scores, which included primary scores and subscores, 1 day before the injury as well as 1, 7, 14, 21, and 28 days after SCI. The scores of the control group increased gradually and reached a plateau at approximately 3 weeks. Significant increases in the BMS scores of SCI mice treated with ADSCs compared to mice in the PBS control group were found beginning on day 14 , and these increases continued until the end of the observation on day $28(P<0.05$, Fig. 1a). Furthermore, our data revealed that ADSC treatment was associated with significantly higher terminal BMS subscores $(P<0.05$, Fig. 1b). The BMS scores in the sham group were significantly higher than those in the PBS control group and ADSC group at any time points. These data demonstrate that ADSC transplantation can significantly ameliorate the functional deficits generated in this mouse model of SCI.

\section{Transplanted ADSCs survived in the injured spinal cord}

Next, we performed immunohistochemical staining to determine the fate of the transplanted cells. The characterization of ADSCs at passage 3 is shown in Fig. 1c.

After they were transduced with a lentiviral vector encoding the GFP reporter gene, most of the ADSCs expressed strong green fluorescence under fluorescence microscopy (Fig. 1d). Four weeks after the transplantation of ADSCs, most of the GFP-positive cells were located around the center of the lesion site (Fig. 1e). No GFP-positive cells were detected in the PBS control group (data not shown). In addition, to evaluate the neural differentiation potential of ADSCs in the spinal cord environment, the expression of neuronal and glial marker proteins was immunohistochemically analyzed 4 weeks after SCI. Double fluorescence immunohistochemistry revealed that ADSCs failed to express the neuronal marker neurofilament, the glial protein GFAP, 

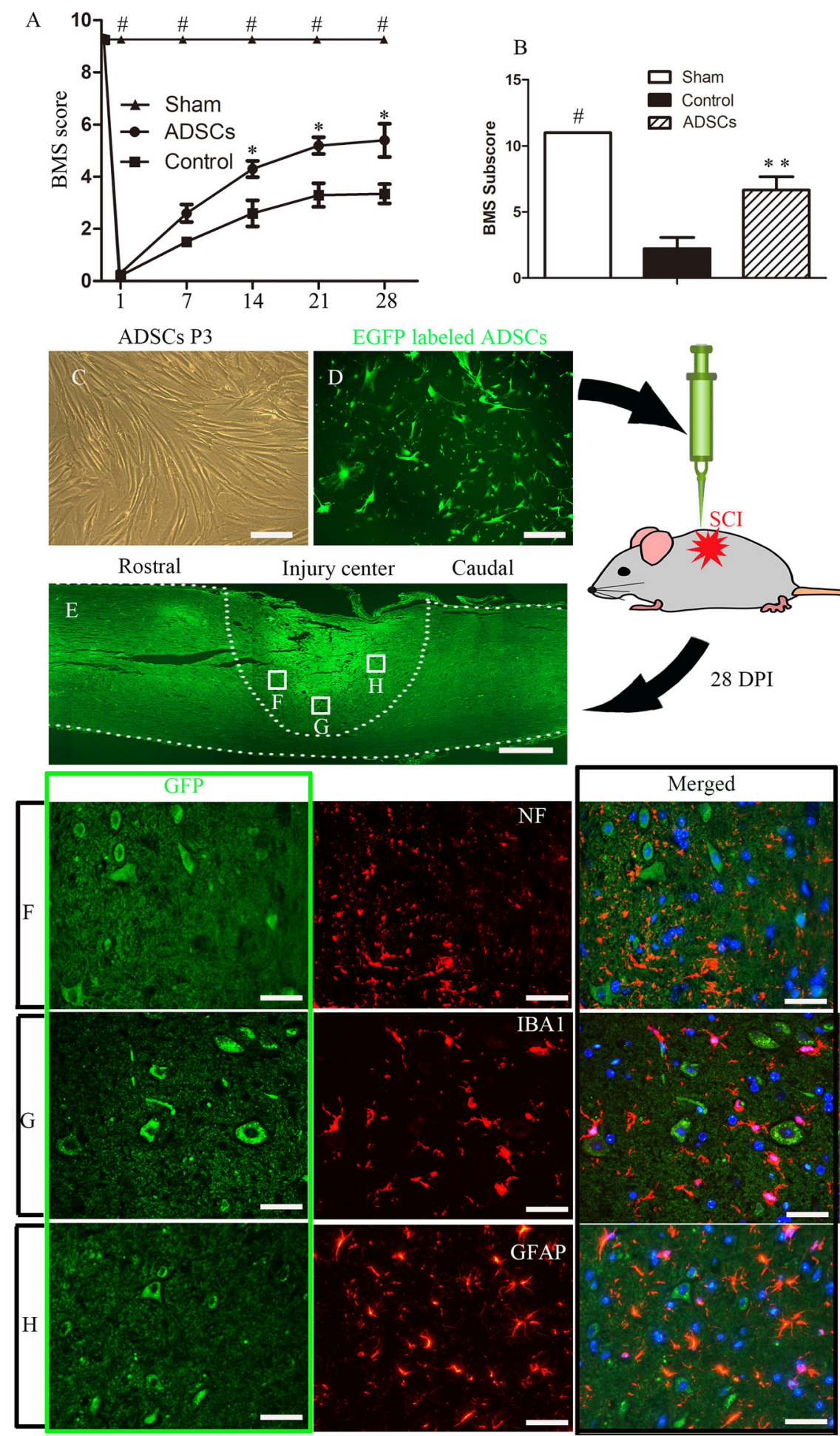

Injury center

Caudal


28 DPI


Fig. 1 Transplanted ADSCS survived in the injured spinal cord in a mouse model of SCI. ADSC treatment promoted the recovery of the locomotor capacity of SCl mice, as evaluated by primary BMS scores (a) at different time points and terminal BMS subscores $(\mathbf{b})\left({ }^{*} P<0.05\right.$ versus the control group; ${ }^{*} P<0.01$ versus the control group; ${ }^{*} P<0.05$ versus the other two groups). $\mathbf{c}$ The morphology of ADSCs in cell culture at passage 3 . Cultured cells showed typically spindle-shaped morphology under phase-contrast microscopy. $\mathbf{d}$ ADSCs infected with GFP reporter genes showed strong fluorescent staining. e A horizontal section of the spinal cord from the ADSC group containing GFP-positive donor cells at the injury site. Double immunofluorescence staining showed that GFP-positive donor cells were negative for the neuronal protein NF200 (f), the microglial marker IBA1 (g), and the glial protein GFAP (h). Scale bars $=100 \mu \mathrm{m}(\mathbf{c}$, d); scale bar $=200 \mu \mathrm{m}(\mathbf{e})$; scale bars $=50 \mu \mathrm{m}(\mathbf{f}-\mathbf{h})$ 
and the microglial marker IBA1 4 weeks after grafting (Fig. 1f-h). ADSCs did not obviously differentiate into neurons, astrocytes, or microglia after transplantation into the acutely injured spinal cords.

\section{ADSC administration inhibited the infiltration of macrophages and reduced the expression of inflammatory cytokines following SCl}

Considering that neural regeneration requires a permissive immune microenvironment, we then explored the effects of ADSC treatment on macrophage/microgliamediated inflammation after SCI. We first examined the mRNA expression of proinflammatory signals, including TNF $\alpha$, IL-1 $\beta$, and IL-6, 3 days after injury. Our data demonstrated that the mRNA levels of TNF $\alpha$, IL-1 $\beta$, and IL-6 were significantly upregulated in the SCI group. Compared with the SCI group, the mRNA levels of TNF $\alpha$, IL- $1 \beta$, and IL- 6 were decreased by $55.61 \pm 3.22 \%$, $48.96 \pm 3.31 \%$, and $42.64 \pm 3.84 \%$, respectively, in the ADSC group (all $P<0.05$ ) (Fig. $2 \mathrm{a}-\mathrm{c}$ ). Meanwhile, the relative fluorescence intensity of the inflammatory infiltrates was analyzed 28 days after injury. In the present study, ED-1 was used as a marker of the activation of resident microglia and extravasated macrophages, while IBA1 was used as a marker of total microglia. We found that the ADSC group exhibited significantly fewer areas of IBA1-positive, ED-1-positive, and GFAP-positive cells than the control group (all $P<0.05$ ) (Fig. $2 \mathrm{~d}, \mathrm{f}-\mathrm{h}$ ). No IBA1-positive and ED-1-positive cells were observed in the spinal cords of sham-operated mice (Fig. 2d). The change in cavity size in the sham group, control group, and ADSC group was also measured. H\&E staining of tissue samples showed a significantly reduced cavity size in the ADSC group compared with the control group $(* P<0.05)$ (Fig. 2e, i).

\section{The Notch signaling pathway was activated in the spinal cords of SCl mice}

To examine the activation of Notch signaling after SCI, we determined the expression profile of NICD, the activated form of Notch1, in the spinal cords of SCI mice $(1,3,7$, and 14 days after injury) and sham mice by western blotting. We found that the NICD expression in the spinal cords of SCI mice began 1 day after the injury, reached a peak at 3 days, and then gradually decreased to baseline at 14 days (Fig. 3a, b). Immunocytochemistry was used to further confirm the expression pattern of NICD, as shown in Fig. 3c. Three days after SCI, NICD staining was predominantly found in the ventral horn of the spinal cord. The intensity of NICD was significantly elevated 3 days after SCI (versus the sham group and at 1 day, $P<0.05)$ and decreased 7 days and 14 days later (Fig. 3c, d). Collectively, these results suggest that Notch1 signaling is activated after SCI.
Neurons were the cells involved in Notch signaling in $\mathrm{SCl}$ mice

To confirm which cell types mediate Notch signaling in the spinal cord, we determined the cellular localization of NICD and Jagged-1 using double immunofluorescence assays. Our results showed that NICD was predominantly localized to NeuN-positive neurons, only a small portion of the IBA1-positive macrophages/microglia were positive for NICD, and no NICD signal was observed in GFAP-positive astrocytes. Jagged1 was abundantly expressed in GFAP-positive astrocytes and NeuNpositive neurons. The expression of Jagged1 in IBA1positive macrophages/microglia was hardly detectable (Fig. 4). Collectively, these results indicate that neurons are the predominant cells involved in Notch signaling activation after SCI.

\section{ADSC treatment inhibited the activation of the Jagged1/ Notch signaling pathway}

To explore the underlying mechanism of ADSC treatment in SCI mice, we performed western blotting to evaluate the expression of Notch1 signaling pathwayassociated factors 3 days after ADSC treatment. The western blotting results demonstrated that $\mathrm{SCI}$ increased the NICD, Jagged1, and RBP-JK expression and that this increase was attenuated after ADSC transplantation (Fig. 5a-d).

\section{Knockdown of the Jagged $1 /$ Notch signaling pathway by Jagged1 siRNA decreased the inflammatory response and protected neuronal integrity}

To confirm the functional implications of Jagged1/ Notch1 activation after SCI, Jagged1 expression was knocked down by injecting a lentivirus containing Jagged1 siRNA into the mouse spinal cord 3 days before SCI modeling. The inflammatory response after SCI was subsequently observed. The western blotting results showed that the protein levels of NICD, Jagged1, and RBP-JK were significantly reduced in the mouse spinal cord 6 days after Jagged1 siRNA injection (3 days after SCI) $(P<0.05$, Fig. 6a-d). We next examined the effect of Jagged1/Notch1 knockdown on the inflammatory response. As shown in Fig. 6e-g, q-PCR examination suggested that Jagged1 siRNA injection significantly decreased the SCI-induced upregulation of the proinflammatory cytokines IL-1 $\beta$ (a), IL-6 (f), and TNF- $\alpha$ (g) at 6 days after Jagged1 siRNA injection (3 days after $\mathrm{SCI})$. The proinflammatory response was always accompanied by neuronal death after SCI. To obtain direct evidence that Jagged1/Notch1 inhibition contributes to neuronal preservation, we further performed NeuN staining to detect surviving neurons in the spinal cord 3, 7,14 , and 28 days after SCI. Viable neurons were defined by strong NeuN staining. Our results showed that from 

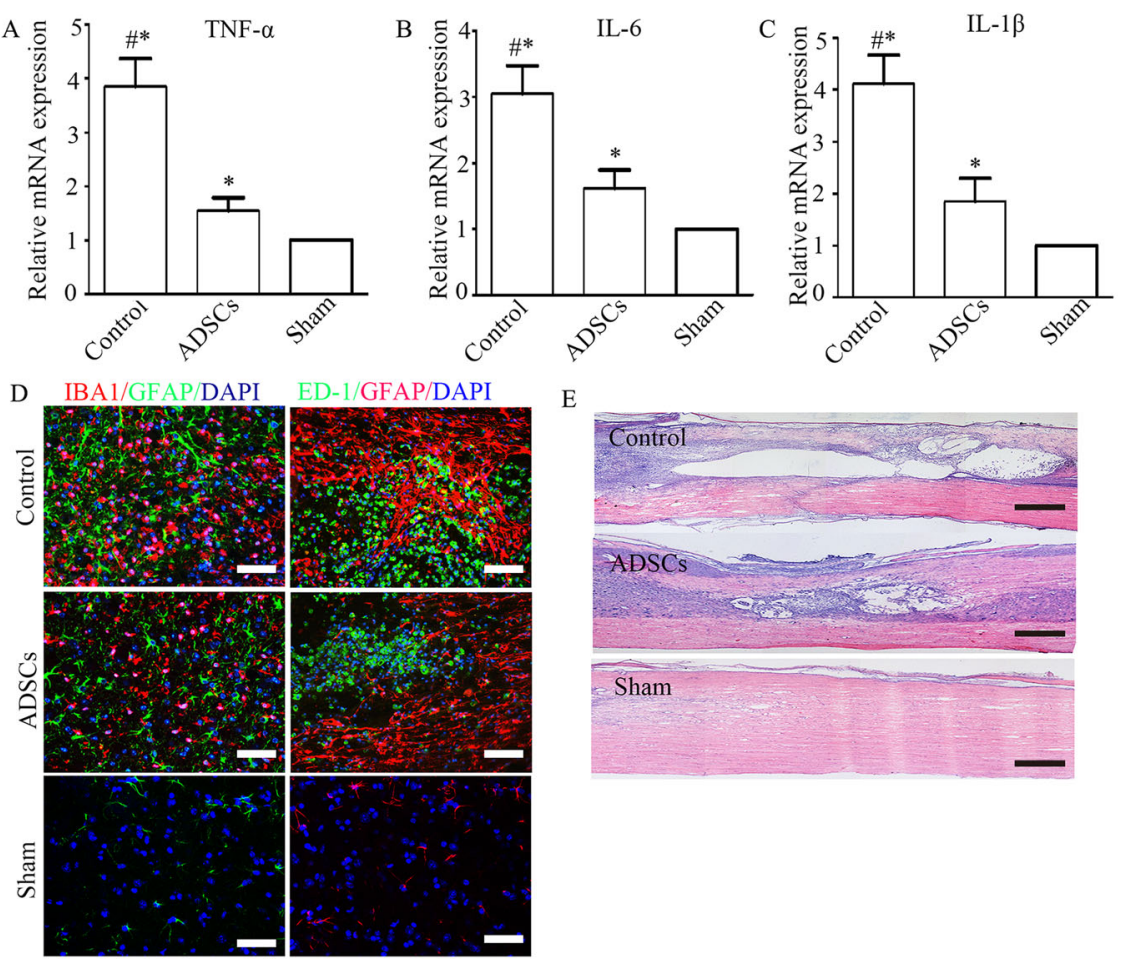

E
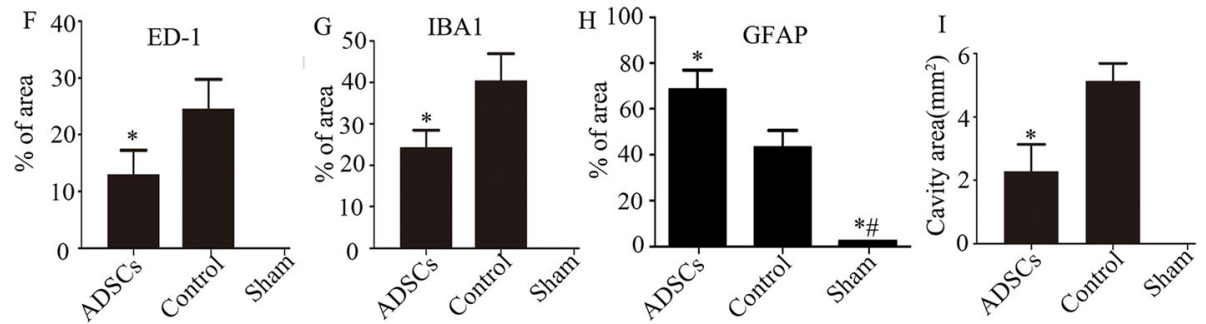

Fig. 2 ADSC administration suppressed the inflammatory response following SCI. ADSC treatment decreased the expression of the proinflammatory cytokines TNF- $\alpha(\mathbf{a}), I L-6(\mathbf{b})$, and IL-1 $\beta$ (c) in the spinal cord tissue at 3 days post-SCI $\left(n=5\right.$; the data are expressed as the mean $\pm S D$; ${ }^{*} P<0.05$ versus the Sham group, ${ }^{\#} P<0.05$ versus the ADSC group). Representative images of double immunohistochemical staining of IBA1 and GFAP (d) and of ED- 1 and GFAP (f) in different groups. Representative images were taken at the boundary of the injury. e Histological images (H\&E staining) of longitudinal sections of the uninjured spinal cord and spinal cords at 28 days post-SCI with different treatments. The quantification of the ED-1-positive (f), IBA1positive $(\mathbf{g})$, and GFAP-positive $(\mathbf{h})$ areas $\left(n=4\right.$; the data are expressed as the mean \pm SD; ${ }^{*} P<0.05$ versus the control group, ${ }^{\#} P<0.05$ versus the ADSC group). $\mathbf{i}$ The cavity area calculated based on H\&E staining $\left(n=4\right.$; the data are expressed as the mean $\pm S D$; ${ }^{*}<<0.05$ versus the control group). Scale bars $=50 \mu \mathrm{m}(\mathbf{d}, \mathbf{f})$; scale bars $=200 \mu \mathrm{m}(\mathbf{e})$

day 7 , the preservation of neuronal integrity in the $\mathrm{SCI}+-$ Jagged1 siRNA-injected group was significantly increased compared to that in the control group and $\mathrm{SCI}+$ scramble siRNA-injected group, while there was no difference between the control group and the $\mathrm{SCI}+\mathrm{s}$ cramble siRNA-injected group (Fig. 6i). Neuronal death was confirmed by activated caspase- $3 / \mathrm{NeuN}$ co-labeling at 7 days after SCI. In the sham group, activated caspase3 immunoreactivity was undetectable. In the spinal cords of SCI control mice and SCI+scramble siRNA-injected mice, activated caspase- 3 immunoreactivity was exhibited in $62.42 \pm 3.44 \%$ and $68.48 \pm 5.64 \%$ of neurons, respectively, which was almost twice as high as the percentage of activated caspase-3-positive neurons observed in the spinal cords of SCI+Jagged1 siRNAinjected mice (Fig. 6h, j).

\section{ADSC protected against Jagged1/Notch pathway- mediated inflammation in neurons subjected to OGD injury}

The in vivo data suggest that ADSC transplantation suppressed the Jagged1/Notch pathway and alleviated the SCI-induced neuroinflammation, neurons were the main cells involved in Notch signaling in SCI mice. We also performed in vitro studies to confirm and further evaluate these results. Concentrations of IL-6, IL-1 $1 \beta$, and TNF- $\alpha$ in conditioned media from neurons with different treatments were measured by ELISA. Our results 


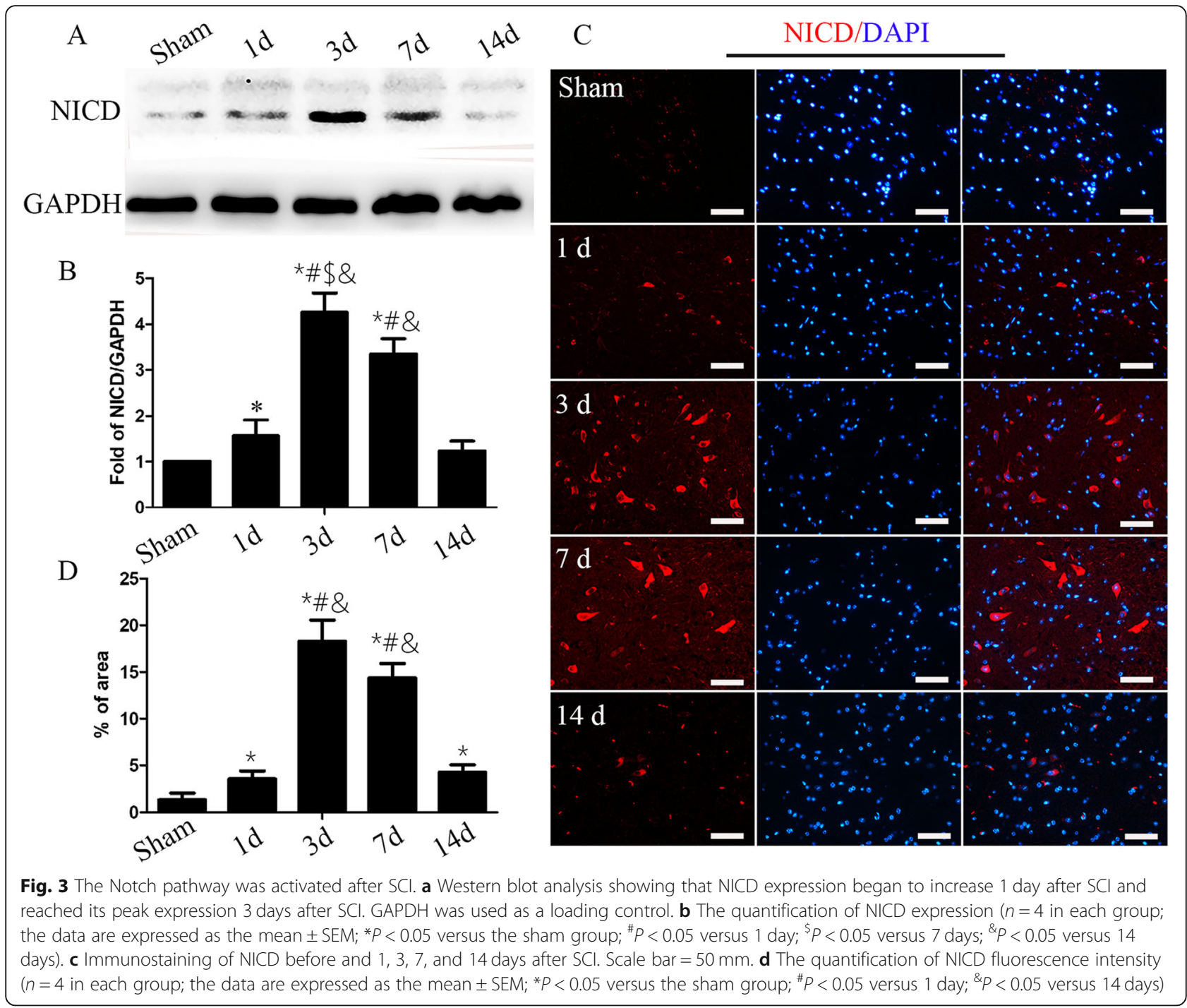

show the concentration of IL-6 from neurons alone was below the detectable level even after they had been exposed to OGD stress for $24 \mathrm{~h}$ (data were not shown). The level of TNF- $\alpha$ and IL-1 $\beta$ secreted from neurons following OGD exposure was significantly increased by more than 3-fold compared with that of non-OGD exposed cells $(P<0.05)$ (Supplementary Fig. 1A, B). ADSC co-culture significantly suppressed the release of TNF- $\alpha$ and IL-1 $\beta$ compared with that in monocultured OGDinjured neurons (Supplementary Fig. 1A, B). The suppressive effect was further enhanced by Jagged1 siRNA treatment, whereas Jagged1 Fc treatment abolished these suppressive effects. Furthermore, we used western blotting to measure the expression of activated caspase 3 in OGD-injured neurons after Jagged1 siRNA or Jagged1 Fc treatment. The changes in the protein expression levels of activated caspase 3 mirrored those of TNF- $\alpha$ and IL-1 $\beta$ following Jagged1 siRNA or Jagged1 Fc treatment (Supplementary Fig. 1C, D).

\section{The JAK/STAT3 pathway is repressed by the inhibition of Jagged 1}

The activation of the JAK/STAT3 pathway has been observed to be correlated with astrocyte reactivity in several types of acute injury. Several reports have shown that there is crosstalk between the Notch pathway and the JAK/STAT3 signaling pathway. We therefore sought to determine whether the inhibition of the Jagged1/ Notch1 signaling pathway can modulate JAK/STAT3 activity. Our western blotting results show that JAK, STAT3, and the phosphorylation of STAT3 (pSTAT3, a marker of activation) were significantly increased at 3 days following SCI but that Jagged1 knockdown significantly reduced this effect compared with that in other 

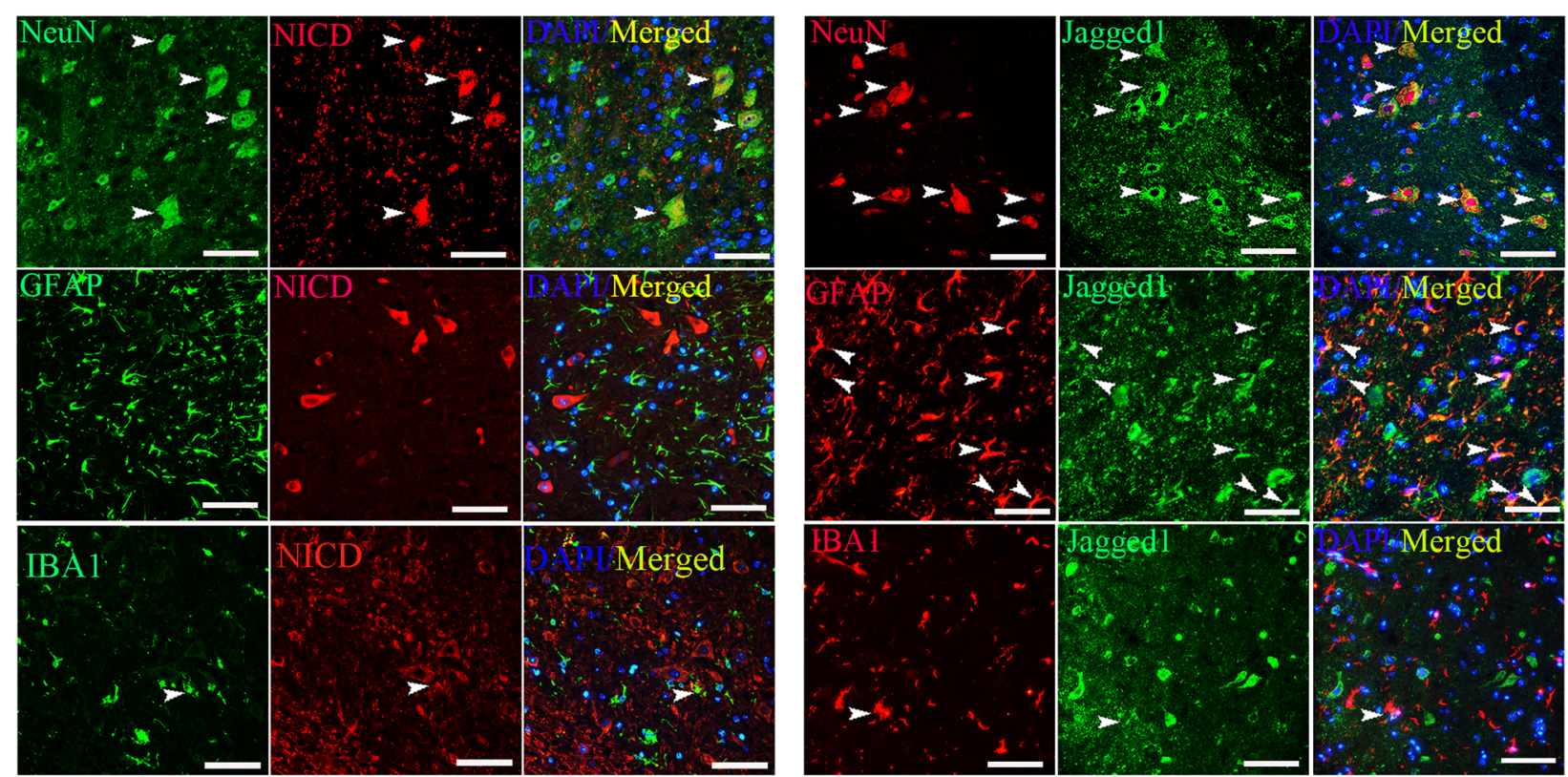

Fig. 4 Neurons were the main cells that mediated Notch signaling after SCI. Double immunofluorescence staining of NICD and Jagged1 in the spinal cords of the SCl group mice 7 days after SCI. The nuclei were stained with DAPI (blue). NICD was mainly localized in NeuN-positive neurons, no NICD signal was observed in astrocytes, and only a small portion of IBA1-positive microglia/macrophages were positive for NICD. Jagged1 was obviously expressed by NeuN-positive neurons and GFAP-positive astrocytes, and the Jagged1 signal in IBA1-positive microglia/ macrophages was weak. Scale bars: $50 \mu \mathrm{m}$

groups (Fig. 7a-d). Next, we investigated the role of STAT3 in reactive astrocytes by examining the protein expression levels of GFAP and pSTAT3 in the spinal cord by double immunofluorescence staining at 3 days after SCI. We found that astrocytes displayed a reactive morphology with enlarged soma and processes and GFAP overexpression. The quantification of the GFAPpositive area showed that there was no significant difference among the three groups at 3 days after SCI (Fig. 7e, g). The level of pSTAT3 was undetectable in uninjured spinal cords (data not shown). In the injured spinal cords, we observed pSTAT3 mainly co-localized with reactive astrocytes. The pSTAT3-positive area in Jagged siRNA-injected mice was markedly smaller than that in scramble siRNA-injected mice and control mice. Moreover, Jagged knockdown strongly reduced the percentage of pSTAT3-positive astrocytes (Fig. 7g, h).

\section{Discussion}

In the present study, we investigated the effect of ADSC transplantation on SCI in a mouse model of acute SCI and elucidated the signaling pathways underlying the functional recovery of SCI mice treated with ADSC transplantation. The results of the present study suggest that the administration of ADSCs immediately after contusion SCI can prevent neuroinflammation, promote neural tissue preservation, and eventually promote functional recovery. These neuroprotective effects are at least partially due to the suppression of Jagged1/Notch1 signaling, which subsequently inhibits JAK/STAT3 phosphorylation.

Recent progress in stem cell biology has opened up an avenue for therapeutic strategies that address the problems encountered in SCI, including the loss of neurons, axonal degeneration, demyelination, disrupted vascular structures, and continuous inflammation [40, 41]. ADSCs are now increasingly being considered optimal stem cells for various therapeutic applications because they are easily obtained and because of their self-renewal ability, multipotency, and lack of immunogenicity [42]. Although the in vitro/vivo transdifferentiation potential of ADSCs and the successful application of ADSCs for cell replacement therapy in various neurological diseases, including SCI, have been reported by some groups, the neural differentiation of MSCs in vivo is still controversial [36, 43-45]. We found no evidence in the present study that ADSCs differentiated into glial or neural cells 4 weeks after transplantation into the injured spinal cords of mice. These findings, along with evidence that the transplantation of ADSCs leads to an improvement in locomotor function and a reduction in neural cell death, support the hypothesis that more complex mechanisms than cellular replacement must be responsible for the therapeutic potential of MSCs.

The inflammation process caused by injury to the spinal cord, including the infiltration of macrophages 


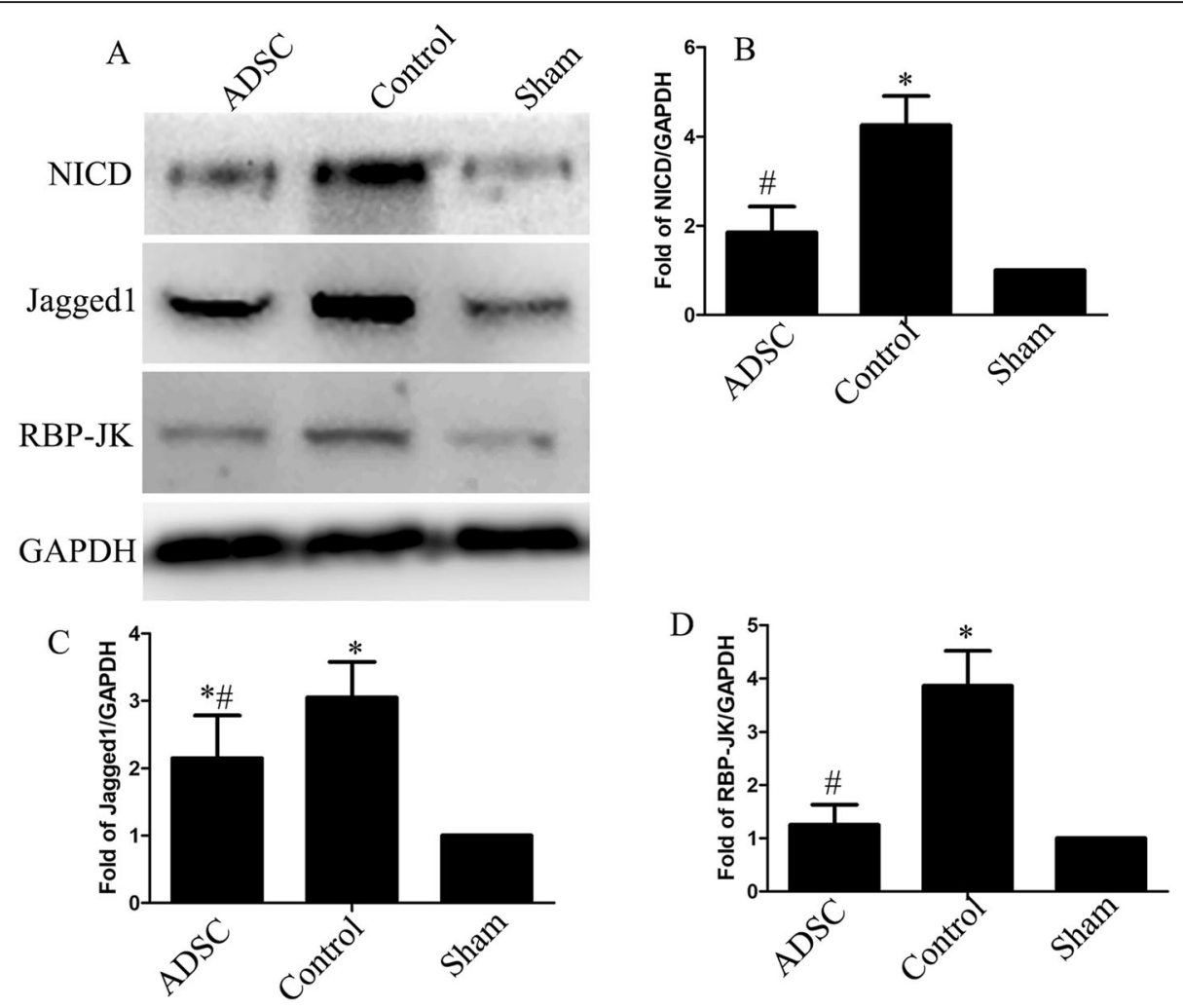

Fig. 5 ADSC transplantation inhibited the SCl-induced upregulation of Notch1 pathway-related molecules. a Representative western blots of Notch1 signaling pathway-associated proteins after ADSC treatment at 3 days post-injury and in the uninjured spinal cords. The quantification of the relative expression levels of NICD (b), Jagged1 (c), and RBP-JK (d) normalized to the level of GAPDH $(n=4$; the data are expressed as the mean \pm SEM; ${ }^{*} P<0.05$ versus the sham group; ${ }^{P} P<0.05$ versus the control group)

into the injured tissue and the secretion of inflammatory cytokines, results in deleterious neurological deficits at the injury site and in the area adjacent to the lesion and is a key component of the progression of SCI [4]. The immunomodulatory potential of ADSCs to reduce the inflammatory response and improve the microenvironment to promote the survival of both transplanted and endogenous cells has been extensively described $[46,47]$. Our findings are in line with these observations. In our present study, by performing immunostaining for ED-1 to label active microglia/macrophages and IBA1 to label all microglia, we observed significant decreases in the numbers of ED-1-positive and IBA1-positive cells upon ADSC transplantation on day 7 after SCI compared to the numbers in the SCI control group. Furthermore, by using q-PCR, we found that ADSC transplantation significantly decreased the expression of proinflammatory cytokines such as IL- 6 , IL-1 $\beta$, and TNF- $\alpha$ in the injured spinal cords. The reduction in macroglia/macrophages was associated with enhanced tissue preservation and eventual functional recovery. These results are not surprising because activated infiltrated macroglia/macrophages are believed to secrete more detrimental and proinflammatory cytokines and factors that contribute to neural cell death after SCI. Collectively, our findings support the notion that anti-inflammation is a key mechanism underlying the therapeutic potential of ADSCs in SCI.

The precise mechanism through which MSCs affect the inflammatory reaction following SCI is still unclear. In recent years, Jagged/Notch1 signaling, which is critical for cell fate decisions and endogenous neurogenesis, has been regarded as a potential therapeutic target for modulating the inflammatory response after CNS injury [27, 48]. Preventing the cleavage of Notch1 into the NICD by $N$-[N-(3,5-difluorophenacetyl-L-alanyl)]-S-phenylglycine t-butyl ester (DAPT, a $\gamma$-secretase inhibitor) augments the regeneration of motor neurons in the injured spinal cords of zebrafish [49] and promotes endogenous neurogenesis and axonal reorganization in a rat stroke model [48]. Arumugam et al. further demonstrated that Notch endangers neurons by modulating pathways that increase their vulnerability to apoptosis and that by activating microglial cells and stimulating the infiltration of proinflammatory leukocytes, the suppression of Notch signaling by DAPT reduces brain damage and improves functional outcomes in a mouse model of stroke [21]. These findings indicate that the 


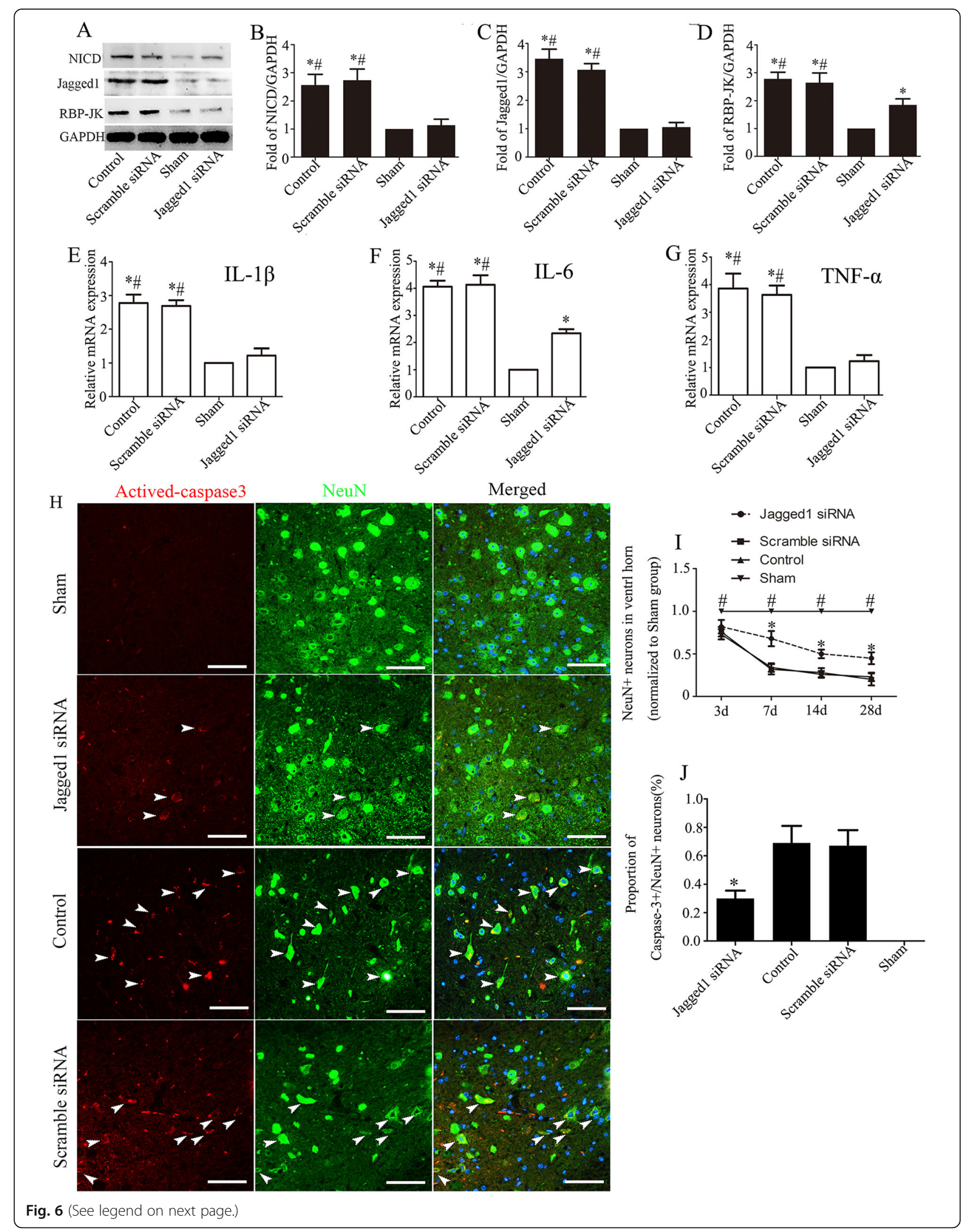






activation of Notch signaling is responsible for the progression of neuroinflammation. Recently, the inhibitory effects of MSC transplantation on Notch1 signaling in various diseases were confirmed by several groups. For example, MSC transplantation alleviates early brain injury in subarachnoid hemorrhage [27] and improves osteopenia in lupus [26] by suppressing Notch1 signaling. Naturally, we hypothesized that ADSC treatment may alleviate the inflammatory response and neurodegeneration by inhibiting the Jagged1/Notch signaling pathway after SCI.

To evaluate the activation of the Notch signaling pathway after SCI, we used western blotting to detect the expression level of NICD (the activated form of Notch1). Our results showed that NICD was maximally activated 3 days post-injury and that its expression was reversed 7 and 14 days after SCI. The western blotting results were further confirmed by immunofluorescence staining. These results are in accordance with a previous study indicating that Notch1 signaling is activated in the acute phase of SCI and then gradually declines in the subacute stage $[50,51]$. Our double immunofluorescence findings showed that NICD was mainly expressed in NeuNpositive neurons. We did not detect NICD in astrocytes, and despite the reported effects of Notch1 in microglia, only very few IBA-positive microglia stained positive for NICD [27, 52, 53]. Jagged1 was found in GFAP-positive astrocytes and NeuN-positive neurons, and very weak Jagged1 immunofluorescence intensity was observed in IBA-positive microglia. Our results indicated that Notch signaling was mainly activated in astrocytes and neurons in the mouse model of SCI used in the present study. Our results are in agreement with several previous studies [22, 54]. The reason for the discrepancy between these studies is unknown, but a possible explanation for the difference in the levels of NICD and Jagged1 in microglia is the different animal strains and animal models used in these studies. Further investigations are needed to explore the exact mechanism. In addition, we found that ADSC administration significantly inhibited the expression of Jagged1/Notch1 and its downstream factors, including Jagged1, NICD, and RBP-JK, compared with that in the SCI control group after SCI. Taken together, our results suggest that ADSC administration immediately after contusion SCI inhibits the activation of the Jagged1/Notch signaling pathway.

To evaluate whether the inhibition of Jagged1/Notch signaling is responsible for the therapeutic potential of ADSCs in SCI mice observed in the present study, we injected a lentivirus containing Jagged1 siRNA into the mouse spinal cord to knock down Jagged1/Notch. Our results show that Jagged1/Notch signaling was significantly suppressed by Jagged 1 siRNA at 3 days postinjection. In addition, the expression of proinflammatory cytokines in injured spinal cords was significantly reduced by Jagged 1 siRNA injection 3 days post-SCI, which was confirmed by measuring the mRNA levels of IL-6, IL-1 $\beta$, and TNF- $\alpha$. We next addressed whether Jagged1 siRNA injection helps maintain neuronal viability. The results of NeuN staining showed that from day 7 , the number of viable, non-atrophic neurons with strong NeuN immunostaining was nearly twofold greater than that in the SCI control group and SCI+scramble siRNA-injected group. Neuronal death was confirmed by activated caspase-3/NeuN co-labeling at 7 days post-SCI. The percentage of activated caspase- $3 / \mathrm{NeuN}$ co-labeling neurons in the ventral horns of SCI control mice and $\mathrm{SCI}+$ scramble siRNA-injected mice was almost twice as high as that in the ventral horns of SCI+Jagged1 siRNAinjected mice. These results suggest that Jagged1/Notch inactivation reduces neuroinflammation and promotes neuronal integrity after SCI. In addition, in our in vitro study, co-culture with ADSC reduced the OGD-induced apoptosis and neuroinflammation in cultured neuronal cells; the protective effects of ADSC against apoptosis and inflammation were reduced by treatment with recombinant Jagged1-Fc protein. Taken together, these results indicate that the therapeutic effects of ADSC transplantation in SCI mice observed in the present study were at least partly due to the inhibition of Jagged1/Notch signaling. As mentioned above, the expression of Notch and its downstream factors in microglia/macrophages is weak, and the molecular mechanism by which the inhibition of the Jagged $1 /$ Notch pathway downregulates the neuroinflammatory response after $\mathrm{SCI}$ needs further investigation. 


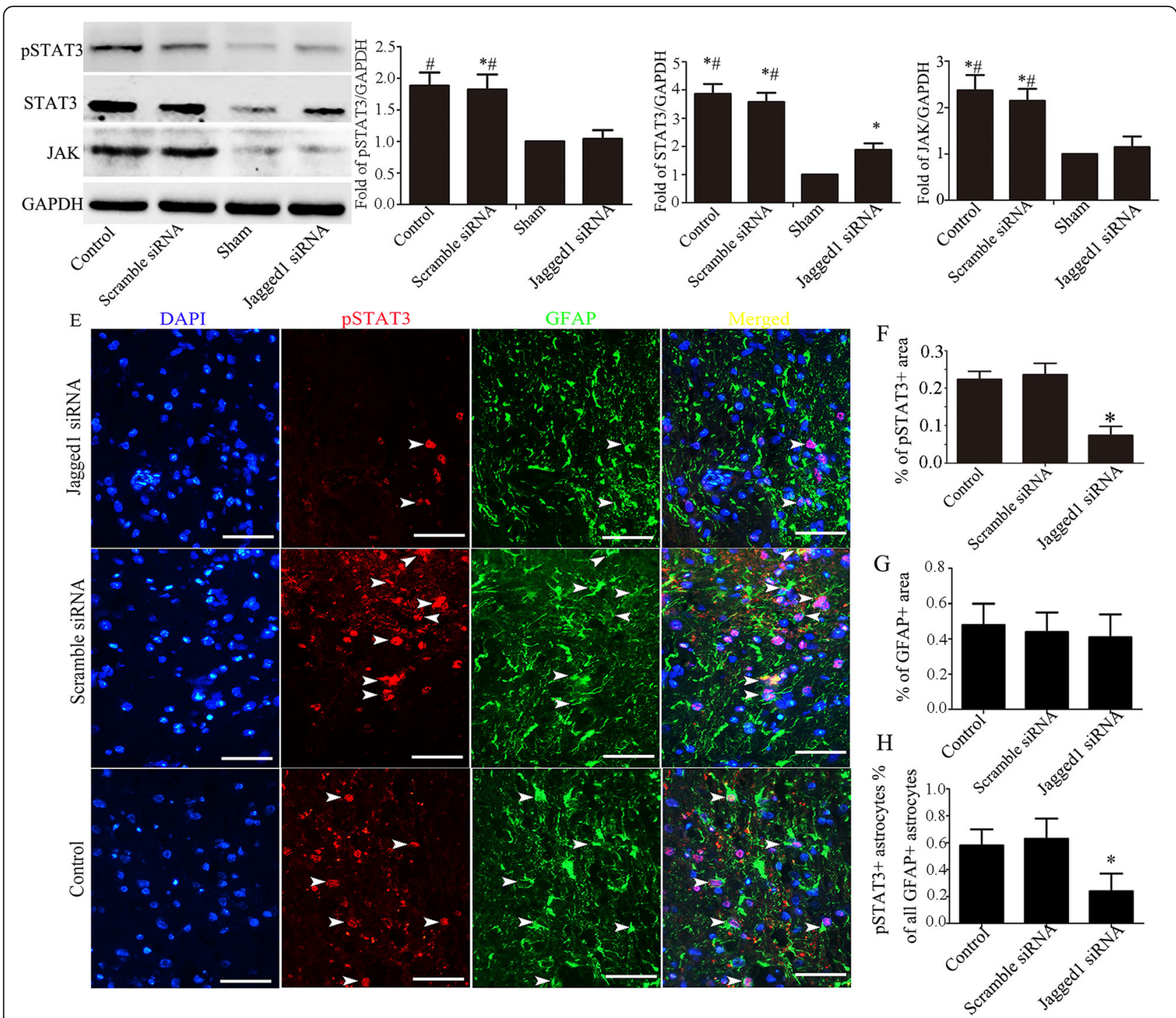

Fig. 7 Jagged1 knockdown inhibited JAK/STAT3 signaling in astrocytes. a Representative western blot images showing the protein levels of JAK STAT3 pathway-related molecules at 3 days after Jagged1 siRNA injection. The quantification of p-STAT3 (b), STAT3 (c), and JAK (d) $(n=4$; the data are expressed as the mean \pm SEM; ${ }^{*} P<0.05$ versus the sham group; ${ }^{\#} P<0.05$ versus the $\mathrm{SCl}+$ scramble siRNA group). e Representative images of the lesion area in the spinal cord sections double-stained for PSTAT3 and GFAP. The cell nuclei were counterstained with DAPI. $\mathbf{f}$ The quantification of the STAT3positive area. Jagged1 siRNA injection significantly reduced the STAT3-positive area at 3 days after SCl. $\mathbf{g}$ The quantification of the GFAP-positive area. There was no significant difference in the GFAP-positive area among the three groups at 3 days after SCI

Astrocytes, as the most abundant cells in the CNS, became reactive in virtually all diseases of the CNS, and this process involves significant transcriptional changes. For example, recent studies have identified at least two types of reactive astrocytes, A1 neurotoxic reactive astrocytes and A2 protective astrocytes [55]. It has been reported that the signaling mechanisms that regulate astrocyte reactivity after SCI are important targets for alleviating neuroinflammation. The Janus kinase/signal transducer and activator of transcription 3 (JAK/Stat3) pathway is a core signaling cascade for the induction and maintenance of astrocyte reactivity $[29,56]$. The activation of Stat3 via phosphorylation by Janus kinases (JAKs) has been demonstrated in a variety of disease models, including SCI [57-59]. The inhibition of this pathway mitigates the neuroinflammatory response and restores synaptic deficits $[59,60]$. Numerous studies have demonstrated a strong association between Notch and Stat3 signaling, and a change in Notch expression can alter Stat3 phosphorylation and activity [32, 61]. More recently, it was demonstrated that the inhibition of the Notch pathway by DAPT suppresses Stat3 activation in astrocytes in SCI rats, facilitating the transformation of astrocytes to the A1 neurotoxic reactive 
astrocyte phenotype and ultimately mitigating inflammation-associated secondary damage following SCI [50]. These studies suggest that Notch signaling can alter the astrocyte phenotype by affecting Stat3 activity and function. In the present study, we explored whether Jagged1/Notch knockdown reduced the activation of JAK/STAT3 in the spinal cord. Our findings suggested that the protein levels of JAK, STAT3, and p-STAT3 were significantly reduced after Jagged1 knockdown 3 days after SCI. Furthermore, by using double immunofluorescence assays, we found that Jagged1/Notch knockdown significantly reduced the percentage of $\mathrm{p}$ STAT3-positive astrocytes compared to that in the control SCI mice. Based on these results, we speculate that Jagged1/Notch signaling may participate in the neuroinflammatory response in SCI by mediating the phosphorylation of the JAK/STAT3 signaling pathway in astrocytes.

\section{Conclusion}

Here, we enhance the understanding of ADSC-based cellular therapy by providing experimental evidence that the neuroprotective effects of ADSCs in the treatment of SCI are associated with Jagged1/Notch signaling. ADSC treatment suppresses the activation of the Jagged1/ Notch pathway after SCI, which inhibits the phosphorylation of JAK/STAT3 and then alleviates the neuroinflammatory response.

\section{Supplementary information}

Supplementary information accompanies this paper at https://doi.org/10 1186/s13287-020-01724-5.

Additional file 1: Table S1. The number of mice in each 8 experimental group of the experiments part 1. Table S2. The number of mice in each experimental group of the experiments in part 2.

Additional file 2: Figure S1. The effect of Jagged1/Notch pathway on inflammation and apoptosis in ADSC co-cultured with neuronal cells.

\begin{abstract}
Abbreviations
MSCs: Mesenchymal stem cells; ADSC: Adipose mesenchymal stem cell; GFP: Green fluorescent protein; IBA1: Ionized calcium-binding adapter molecule 1; JAKSSTAT3: Janus tyrosine kinase/signal transducer and activator of transcription; SCI: Spinal cord injury; CNS: Central nervous system; NICD: Notch intracellular domain; GFAP: Glial fibrillary acidic protein; TNFa: Tumor necrosis factor alpha; IL: Interleukin; ANOVA: Analysis of variance; siRNA: Small interfering RNA; RBP-JK: Recombining binding protein suppressor of hairless; BMS: Basso Mouse Scale
\end{abstract}

\section{Acknowledgements}

We would like to acknowledge Luo Shiming at the Fertility Preservation Lab, Reproductive Medicine Center, Guangdong Second Provincial General Hospital, and Liu Shuang at the Department of Hematology, Guangdong Second Provincial General Hospital for the technical assistance.

\section{Authors' contributions}

ZZL designed the research, collected and analyzed the data, and drafted the manuscript. TXB performed the main part of the experiments. MBL and WYY discussed the results and edited the manuscript. XHL contributed to the western blotting and QPCR analysis. HLS helped establish the SCI models.
$H Z X, Y S, X H$, and $Z L$ participated in the cell culture and animal behavioral tests. ZH contributed to the conception and design and supervised the study. All authors critically reviewed and approved the submitted version of the manuscript

\section{Funding}

This work was supported by the National Natural Science Foundation of China (no. 81400996) and the Natural Science Foundation of Guangdong Province, China (no. 2016A030313627)

\section{Availability of data and materials}

All data generated or analyzed during this study are included in this published article.

\section{Ethics approval and consent to participate}

All experimental procedure was approved by the Guangdong Second Provincial General Hospital Ethics Committee, Guangzhou, China. All protocols were performed to minimize pain or discomfort.

\section{Consent for publication}

Not applicable.

\section{Competing interests}

The authors declare that they have no competing interests.

\section{Author details}

${ }^{1}$ The Spine Department, Orthopaedic Center, Guangdong Second Provincial General Hospital, Guangzhou, China. ${ }^{2}$ The Second School of Clinical Medicine, Southern Medical University, Guangzhou, China. ${ }^{3}$ Department of Cardiology, Liwan Central Hospital of Gaungzhou, Guangzhou, China. ${ }^{4}$ Department of Anesthesiology, Zhu Jiang Hospital, Southern Medical University, Guangzhou, China.

Received: 20 February 2020 Revised: 29 April 2020

Accepted: 11 May 2020 Published online: 03 June 2020

\section{References}

1. Fitzharris M, Cripps RA, Lee BB. Estimating the global incidence of traumatic spinal cord injury. Spinal Cord. 2014;52:117-22.

2. Sofroniew MV. Dissecting spinal cord regeneration. Nature. 2018;557:343-50

3. Gensel JC, Zhang B. Macrophage activation and its role in repair and pathology after spinal cord injury. Brain Res. 1619;2015:1-11.

4. O'Shea TM, Burda JE, Sofroniew MV. Cell biology of spinal cord injury and repair. J Clin Invest. 2017:127:3259-70.

5. Qu J, Zhang H. Roles of mesenchymal stem cells in spinal cord injury. Stem Cells Int. 2017:2017:5251313.

6. Chung TN, Kim JH, Choi BY, Chung SP, Kwon SW, Suh SW. Adipose-derived mesenchymal stem cells reduce neuronal death after transient global cerebral ischemia through prevention of blood-brain barrier disruption and endothelial damage. Stem Cells Transl Med. 2015:4:178-85.

7. Cheng Z, Wang L, Qu M, Liang H, Li W, Li Y, et al. Mesenchymal stem cells attenuate blood-brain barrier leakage after cerebral ischemia in mice. J Neuroinflammation. 2018:15:135

8. Uccelli A, Laroni A, Freedman MS. Mesenchymal stem cells for the treatment of multiple sclerosis and other neurological diseases. Lancet Neurol. 2011;10:649-56.

9. Neirinckx V, Agirman G, Coste C, Marquet A, Dion V, Rogister B, et al. Adult bone marrow mesenchymal and neural crest stem cells are chemoattractive and accelerate motor recovery in a mouse model of spinal cord injury. Stem Cell Res Ther. 2015;6:211.

10. Cheng H, Liu X, Hua R, Dai G, Wang X, Gao J, et al. Clinical observation of umbilical cord mesenchymal stem cell transplantation in treatment for sequelae of thoracolumbar spinal cord injury. J Transl Med. 2014;12:253.

11. Nandoe TR, Hurtado A, Ritfeld GJ, Rahiem ST, Wendell DF, Barroso MM, et al Bone marrow stromal cells elicit tissue sparing after acute but not delayed transplantation into the contused adult rat thoracic spinal cord. J Neurotrauma. 2009;26:2313-22.

12. Yoshihara T, Ohta M, Itokazu Y, Matsumoto N, Dezawa M, Suzuki Y, et al. Neuroprotective effect of bone marrow-derived mononuclear cells promoting functional recovery from spinal cord injury. J Neurotrauma. 2007; 24:1026-36. 
13. Zhou Z, Chen Y, Zhang H, Min S, Yu B, He B, et al. Comparison of mesenchymal stromal cells from human bone marrow and adipose tissue for the treatment of spinal cord injury. Cytotherapy. 2013;15:434-48.

14. Leu S, Lin YC, Yuen CM, Yen CH, Kao YH, Sun CK, et al. Adipose-derived mesenchymal stem cells markedly attenuate brain infarct size and improve neurological function in rats. J Transl Med. 2010;8:63.

15. Zhou F, Gao S, Wang L, Sun C, Chen L, Yuan P, et al. Human adiposederived stem cells partially rescue the stroke syndromes by promoting spatial learning and memory in mouse middle cerebral artery occlusion model. Stem Cell Res Ther. 2015;6:92.

16. Siebel C, Lendahl U. Notch signaling in development, tissue homeostasis, and disease. Physiol Rev. 2017;97:1235-94.

17. Stump G, Durrer A, Klein A, Lutolf S, Suter U, Taylor V. Notch1 and its ligands Delta-like and Jagged are expressed and active in distinct cell populations in the postnatal mouse brain. Mech Develop. 2002;114:153-9.

18. Gopalakrishnan N, Sivasithamparam ND, Devaraj H. Synergistic association of Notch and NFKB signaling and role of Notch signaling in modulating epithelial to mesenchymal transition in colorectal adenocarcinoma. Biochimie. 2014;107(Pt B):310-8.

19. Kopan R, llagan MXG. The canonical Notch signaling pathway: unfolding the activation mechanism. Cell. 2009;137:216-33.

20. Caraballo-Miralles V, Cardona-Rossinyol A, Garcera A, Torres-Benito L, Soler $R M$, Tabares $L$, et al. Notch signaling pathway is activated in motoneurons of spinal muscular atrophy. Int J Mol Sci. 2013;14:11424-37.

21. Arumugam TV, Chan SL, Jo DG, Yilmaz G, Tang SC, Cheng A, et al. Gamma secretase-mediated Notch signaling worsens brain damage and functional outcome in ischemic stroke. Nat Med. 2006;12:621-3.

22. Nonneman A, Criem N, Lewandowski SA, Nuyts R, Thal DR, Pfrieger FW, et al. Astrocyte-derived Jagged-1 mitigates deleterious Notch signaling in amyotrophic lateral sclerosis. Neurobiol Dis. 2018;119:26-40.

23. Ohuchi $K$, Funato $M$, Yoshino $Y$, Ando $S$, Inagaki $S$, Sato $A$, et al. Notch signaling mediates astrocyte abnormality in spinal muscular atrophy model systems. Sci Rep. 2019;9:3701.

24. Zhao Y, Lai W, Xu Y, Li L, Chen Z, Wu W. Exogenous and endogenous therapeutic effects of combination sodium ferulate and bone marrow stromal cells (BMSCs) treatment enhance neurogenesis after rat focal cerebral ischemia. Metab Brain Dis. 2013;28:655-66.

25. Xing Y, Chen X, Cao Y, Huang J, Xie X, Wei Y. Expression of Wnt and Notch signaling pathways in inflammatory bowel disease treated with mesenchymal stem cell transplantation: evaluation in a rat model. Stem Cell Res Ther. 2015;6:101.

26. Liu S, Liu D, Chen C, Hamamura K, Moshaverinia A, Yang R, et al. MSC transplantation improves osteopenia via epigenetic regulation of Notch signaling in lupus. Cell Metab. 2015;22:606-18.

27. Liu W, Li R, Yin J, Guo S, Chen Y, Fan H, et al. Mesenchymal stem cells alleviate the early brain injury of subarachnoid hemorrhage partly by suppression of Notch1-dependent neuroinflammation: involvement of Botch. J Neuroinflammation. 2019;16:8.

28. Wanner IB, Anderson MA, Song B, Levine J, Fernandez A, GrayThompson Z, et al. Glial scar borders are formed by newly proliferated, elongated astrocytes that interact to corral inflammatory and fibrotic cells via STAT3-dependent mechanisms after spinal cord injury. J Neurosci. 2013:33:12870-86.

29. Ben HL, Ceyzeriat K, Carrillo-de SM, Aubry F, Auregan G, Guillermier M, et al. The JAK/STAT3 pathway is a common inducer of astrocyte reactivity in Alzheimer's and Huntington's diseases. J Neurosci. 2015;35:2817-29.

30. Justicia C, Gabriel C, Planas AM. Activation of the JAK/STAT pathway following transient focal cerebral ischemia: signaling through Jak1 and Stat3 in astrocytes. Glia. 2000;30:253-70.

31. Okada S, Nakamura M, Katoh H, Miyao T, Shimazaki T, Ishii K, et al. Conditional ablation of Stat3 or Socs3 discloses a dual role for reactive astrocytes after spinal cord injury. Nat Med. 2006;12:829-34.

32. Yang J, Xing H, Lu D, Wang J, Li B, Tang J, et al. Role of Jagged1/STAT3 signalling in platinum-resistant ovarian cancer. J Cell Mol Med. 2019;23: 4005-18.

33. Chen X, Su J, Feng J, Cheng L, Li Q, Qiu C, et al. TRIM72 contributes to cardiac fibrosis via regulating STAT3/Notch-1 signaling. J Cell Physiol. 2019; 234:17749-56.

34. LeComte MD, Shimada IS, Sherwin C, Spees JL. Notch1-STAT3-ETBR signaling axis controls reactive astrocyte proliferation after brain injury. P Natl Acad Sci Usa. 2015;112:8726-31.
35. Staff NP, Madigan NN, Morris J, Jentoft M, Sorenson EJ, Butler G, et al. Safety of intrathecal autologous adipose-derived mesenchymal stromal cells in patients with ALS. Neurology. 2016;87:2230-4.

36. Gao S, Guo X, Zhao S, Jin Y, Zhou F, Yuan P, et al. Differentiation of human adipose-derived stem cells into neuron/motoneuron-like cells for cell replacement therapy of spinal cord injury. Cell Death Dis. 2019;10. PMID: 31395857, PMCID: PMC6687731. https://doi.org/10.1038/s41419-019-1772-1.

37. Ding X, Li Y, Liu Z, Zhang J, Cui Y, Chen X, et al. The sonic hedgehog pathway mediates brain plasticity and subsequent functional recovery after bone marrow stromal cell treatment of stroke in mice. J Cereb Blood Flow Metab. 2013;33:1015-24.

38. Bellver-Landete V, Bretheau F, Mailhot B, Vallieres N, Lessard M, Janelle M, et al. Microglia are an essential component of the neuroprotective scar that forms after spinal cord injury. Nat Commun. 2019;10:518.

39. Basso DM, Fisher LC, Anderson AJ, Jakeman LB, DM MT, Popovich PG. Basso Mouse Scale for locomotion detects differences in recovery after spinal cord injury in five common mouse strains; 2006. p. 635-59.

40. Kim BG, Hwang DH, Lee SI, Kim EJ, Kim SU. Stem cell-based cell therapy for spinal cord injury. Cell Transplant. 2007;16:355-64.

41. Sahni V, Kessler JA. Stem cell therapies for spinal cord injury. Nat Rev Neurol. 2010;6:363-72.

42. Zhu Y, Liu T, Song K, Fan X, Ma X, Cui Z. Adipose-derived stem cell: a better stem cell than BMSC. Cell Biochem Funct. 2008:26:664-75.

43. Arboleda D, Forostyak S, Jendelova P, Marekova D, Amemori T, Pivonkova $H$ et al. Transplantation of predifferentiated adipose-derived stromal cells for the treatment of spinal cord injury002E. Cell Mol Neurobiol. 2011;31:111322. https://doi.org/10.1007/s10571-011-9712-3.

44. Liu Y, Seckin H, Izci Y, Du ZW, Yan Y, Baskaya MK. Neuroprotective effects of mesenchymal stem cells derived from human embryonic stem cells in transient focal cerebral ischemia in rats. J Cereb Blood Flow Metab. 2009;29: 780-91.

45. Sasaki M, Radtke C, Tan AM, Zhao P, Hamada H, Houkin K, et al. BDNFhypersecreting human mesenchymal stem cells promote functional recovery, axonal sprouting, and protection of corticospinal neurons after spinal cord injury. J Neurosci. 2009;29:14932-41.

46. Shi Y, Hu G, Su J, Li W, Chen Q, Shou P, et al. Mesenchymal stem cells: a new strategy for immunosuppression and tissue repair. Cell Res. 2010;20:510-8.

47. Chung TN, Kim JH, Choi BY, Jeong J, Chung SP, Kwon SW, et al. Effect of adipose-derived mesenchymal stem cell administration and mild hypothermia induction on delayed neuronal death after transient global cerebral ischemia. Crit Care Med. 2017;45:e508-15.

48. Hao XZ, Yin LK, Tian JQ, Li CC, Feng XY, Yao ZW, et al. Inhibition of Notch1 signaling at the subacute stage of stroke promotes endogenous neurogenesis and motor recovery after stroke. Front Cell Neurosci. 2018;12:245.

49. Dias TB, Yang YJ, Ogai K, Becker T, Becker CG. Notch signaling controls generation of motor neurons in the lesioned spinal cord of adult zebrafish. J Neurosci. 2012;32:3245-52.

50. Qian D, Li L, Rong Y, Liu W, Wang Q, Zhou Z, et al. Blocking Notch signal pathway suppresses the activation of neurotoxic A1 astrocytes after spinal cord injury. Cell Cycle. 2019;18(21):3010-29. https://doi.org/10.1080/ 15384101.2019.1667189.

51. Khazaei M, Ahuja CS, Nakashima H, Nagoshi N, Li L, Wang J, et al. GDNF rescues the fate of neural progenitor grafts by attenuating Notch signals in the injured spinal cord in rodents. Sci Transl Med. 2020;12. PMID: 31915299. https://doi.org/10.1126/scitransImed.aau3538.

52. Yao L, Kan EM, Kaur C, Dheen ST, Hao A, Lu J, et al. Notch-1 signaling regulates microglia activation via NF-kB pathway after hypoxic exposure in vivo and in vitro. PLoS One. 2013;8:e78439.

53. Zeng W, Han Y, Zhu G, Huang L, Deng Y, Wang Q, et al. Hypertonic saline attenuates expression of Notch signaling and proinflammatory mediators in activated microglia in experimentally induced cerebral ischemia and hypoxic BV-2 microglia. BMC Neurosci. 2017;18:32.

54. Sun F, Mao X, Xie L, Ding M, Shao B, Jin K. Notch1 signaling modulates neuronal progenitor activity in the subventricular zone in response to aging and focal ischemia. Aging Cell. 2013;12:978-87.

55. Liddelow SA, Guttenplan KA, Clarke LE, Bennett FC, Bohlen CJ, Schirmer L, et al. Neurotoxic reactive astrocytes are induced by activated microglia. Nature. 2017:541:481-7.

56. Tyzack GE, Sitnikov S, Barson D, Adams-Carr KL, Lau NK, Kwok JC, et al. Astrocyte response to motor neuron injury promotes structural synaptic plasticity via STAT3-regulated TSP-1 expression. Nat Commun. 2014;5:4294. 
57. Herrmann JE, Imura T, Song B, Qi J, Ao Y, Nguyen TK, et al. STAT3 is a critical regulator of astrogliosis and scar formation after spinal cord injury. J Neurosci. 2008;28:7231-43.

58. Hristova M, Rocha-Ferreira E, Fontana X, Thei L, Buckle R, Christou M, et al. Inhibition of signal transducer and activator of transcription 3 (STAT3) reduces neonatal hypoxic-ischaemic brain damage. J Neurochem. 2016;136: 981-94.

59. Reichenbach N, Delekate A, Plescher M, Schmitt F, Krauss S, Blank N, et al. Inhibition of Stat3-mediated astrogliosis ameliorates pathology in an Alzheimer's disease model. Embo Mol Med. 2019;11. PMID: 30617153, PMCID: PMC6365929. https://doi.org/10.15252/emmm.201809665.

60. Ceyzeriat K, Ben HL, Denizot A, Pommier D, Matos M, Guillemaud O, et al. Modulation of astrocyte reactivity improves functional deficits in mouse models of Alzheimer's disease. Acta Neuropathol Commun. 2018;6:104.

61. Hildebrand D, Uhle F, Sahin D, Krauser U, Weigand MA, Heeg K. The interplay of Notch signaling and STAT3 in TLR-activated human primary monocytes. Front Cell Infect Mi. 2018;8:241.

\section{Publisher's Note}

Springer Nature remains neutral with regard to jurisdictional claims in published maps and institutional affiliations.

Ready to submit your research? Choose BMC and benefit from:

- fast, convenient online submission

- thorough peer review by experienced researchers in your field

- rapid publication on acceptance

- support for research data, including large and complex data types

- gold Open Access which fosters wider collaboration and increased citations

- maximum visibility for your research: over $100 \mathrm{M}$ website views per year

At BMC, research is always in progress.

Learn more biomedcentral.com/submissions 